A 12102 เ9?683

NATL INST OF STANDAROS \& TECH R.I.C.

H

. A. . . .

A11102697683

Darwitt, Willam C/Horn design equations
OC100.U56 NO.87-3073 $1987^{\circ}$ V19 C.1 NBS-P

HURN UESIGN EQUATIONS FOR THE NBS HORN-TYPE NOISE STANDARDS

William C. Daywitt

National Bureau of Standards

U.S. Department of Commerce

Boulder, Colorado 80303-3328

August 1987 



\section{HORN DESIGN EQUATIONS FOR THE NBS HORN-TYPE NOISE STANDARDS}

William C. Daywitt

Electromagnetic Fields Division

Center for Electronics and Electrical Engineering

National Engineering Laboratory

National Bureau of Standards

Boulder, Colorado 80303-3328

August 1987

Sponsored in part by

The Space Systems \& Command, Control, \& Communications

USAF, Washington, DC

and

The Naval Ocean Systems Center (NOSC)

San Diego, California

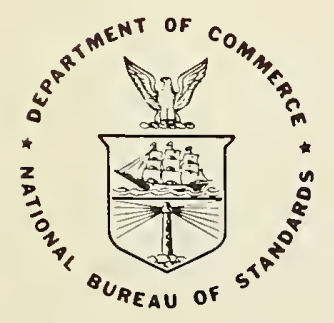

U.S. DEPARTMENT OF COMMERCE, Clarence J. Brown, Acting Secretary 


\section{CONTENTS}

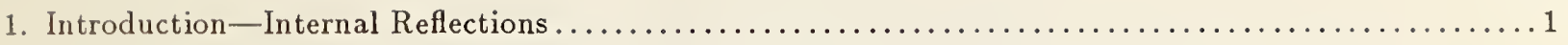

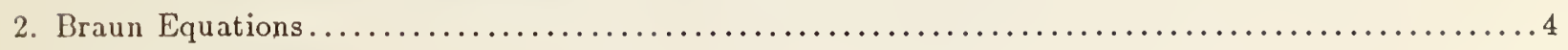

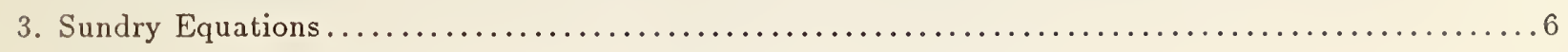

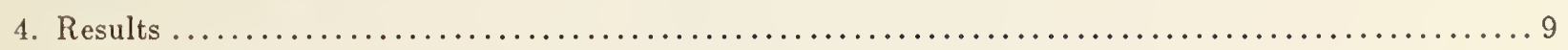

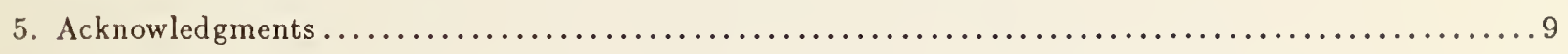

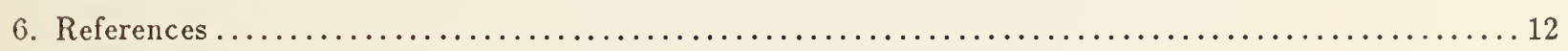

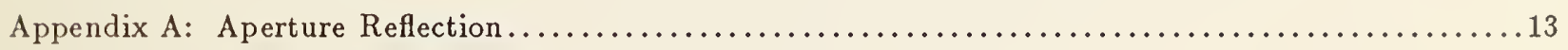





\title{
Horn Design Equations for the NBS Horn-Type Noise Standards
}

\author{
W. C. Daywitt
}

Equations are given for calculating the interior dimensions of the horn pickup in the NBS millimeter wave noise standards. These dimensions insure negligible internal horn reflections, resulting in an accurate calculation of the horn attenuation. Measurements in the WR10 horn show a reflection of magnitude less than 0.001 .

Key words: electromagnetic horn; millimeter wave; noise source; reflection coefficient.

\section{Introduction-Internal Reflections}

The National Bureau of Standards (NBS) horn-type cryogenic reference noise standards [1] consist of a noisy cavity and a pyramidal horn pickup. Their output noise temperatures are the sum of the cavity temperature and the excess noise temperature generated by the dissipative horn loss. An accurate calculation of the horn loss requires a knowledge of the magnetic field parallel to the internal horn surfaces, so the horn must be structured to allow for an accurate prediction of that field.

Figure 1 shows an E-plane cross sectional view of one of the millimeter wave horns. The waveguide (wg) and early flare portions are surrounded by a water jacket to maintain them at a uniform temperature close to ambient. As is well known, no solutions for the field patterns inside the pyramidal flare exist. However, by using a gradual (small angle) flare it is possible to maintain the $T E_{10}$ mode field pattern generated in the waveguide portion of the horn far into the flare as long as the discontinuities at the wg-flare transition and at the aperture are minimized.

The wg section of the horn in figure 1 is chosen just long enough to filter out higher-order modes generated in the horn flare by the cavity radiation, but otherwise as short as possible to achieve a minimum loss [1]. In particular, the wg is chosen to keep the output noise temperature due to higher modes below $0.1 \%$ of the total output at the highest operating frequency of the noise source. Table 1 is a list of these minimum wg lengths for the wg bands from WR90 to WR10. The first column lists the various wg bands by their WR designations with their corresponding frequency ranges listed in column two. The wg length $x_{1}$ required to produce a $0.1 \%$ higher mode error is listed in column three. Thus, as long as the wg portion of the horn is $x_{1}$ or longer, the output noise temperature of the source is contaminated by less than $0.1 \%$ of the higher-mode energy.

A schematic cross sectional view of a horn antenna is shown in figure 2, indicating the wg flange $F$, the wg-flare butt joint $A$, and the aperture edges $B$. The double arrows depict surface currents caused by fields entering the flange and exiting the aperture. Significant diffraction (single arrows) occurs at the joint and aperture because of the abrupt edges at $\mathrm{A}$ and $\mathrm{B}$, which in turn disturb the desired $T E_{10}$ mode field pattern and lead to errors in the calculated horn loss.

To reduce the diffraction effect at the butt joint a smooth circular arc from wg to flare is made. Figure 3 shows this transition region for the $\mathrm{E}-$ and $\mathrm{H}$-plane cross sections of the horn, where for convenience only the 


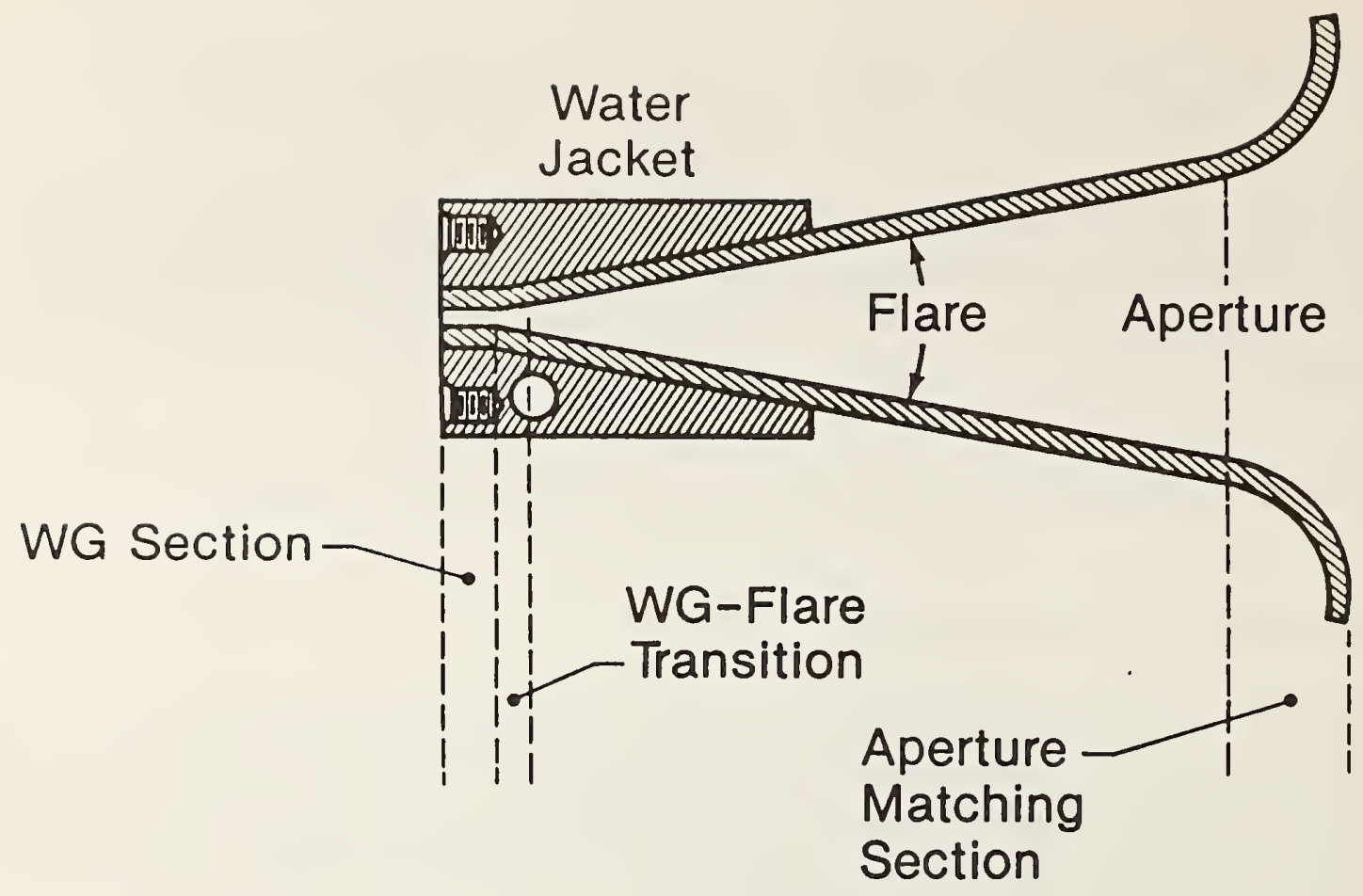

Figure 1. A simplified E-plane cross section of the WR10 millimeter wave horn.

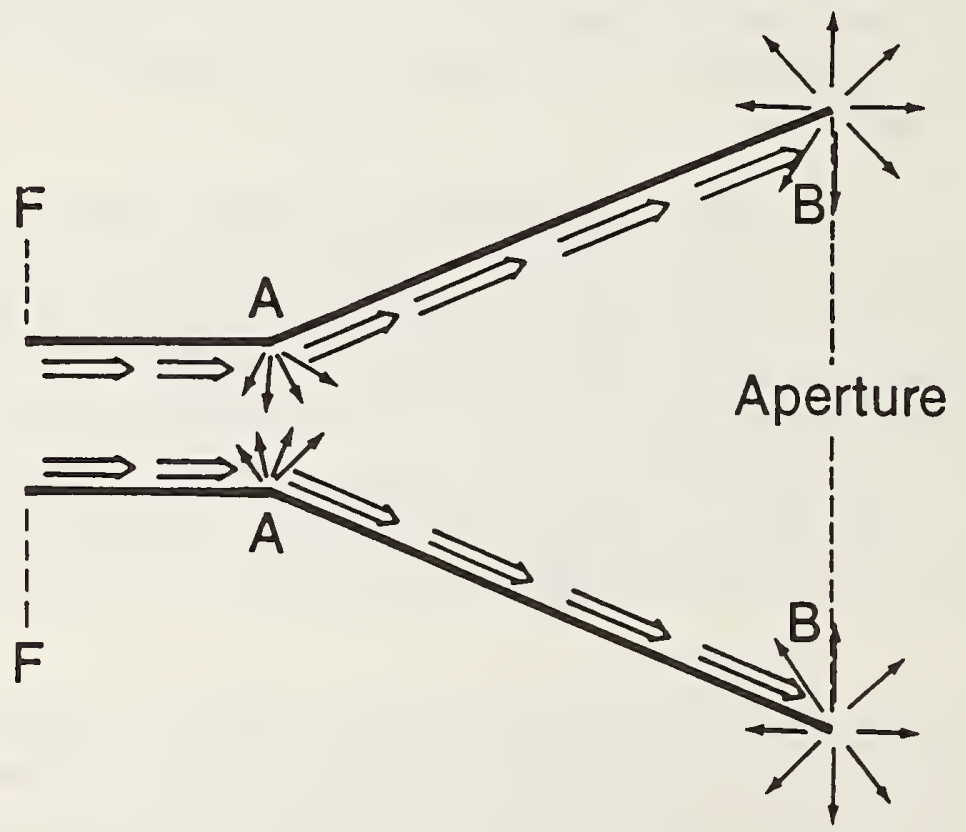

Figure 2. A schematic diagram of the interior horn surfaces indicating the surface currents and the diffraction points. 
upper horn walls are drawn. The dashed lines show the butt geometry before the transitions are included. The narrow and wide dimensions of the wg are denoted by $b_{0}$ and $a_{0}$ respectively. The radius of the arc in the E-plane is $r_{e}$ and in the $\mathrm{H}$-plane it is $r_{h}$. The flare angles in these planes are $\phi_{e}$ and $\phi_{h}$. Terzuoli \& Peters $\{2 \mid$ found that the reflection at the butt joint due to the diffraction is markedly reduced if the length of the arc $r_{e} \phi_{e}$ in the E-plane is $0.4 \lambda$ or greater, where $\lambda$ is the free space wavelength corresponding to the lowest frequency in the WR band, i.e. the maximum free space wavelength. To be safe the following relation is adhered to in the horn design (see figure 5 for $z_{0}$ ):

$$
z_{0}=0.4 \lambda
$$

This leads to

$$
r=z_{0} \sin \phi /(1-\cos \phi)
$$

or

$$
r \phi \doteq 0.8 \lambda
$$

(twice the value suggested by Terzuoli \& Peters) for both the $\mathrm{E}-$ and $\mathrm{H}$-planes. Both $r_{e}$ and $r_{h}$ are determined from equation (1.2) by inserting $\phi_{e}$ and $\phi_{h}$ respectively. Up to this point only $x_{1}, z_{0}$, and the relatio: in equation (1.2) have been determined. The narrow aperture dimension $\mathrm{b}$ is found next.

\section{Table 1. MINIMUM WG LENGTH $x_{1}$ FOR $0.1 \%$ OUTPUT ERROR}

$\begin{array}{lcl}W R & \text { Freq Range }(\mathrm{GHz}) & x_{1}(\mathrm{~cm}) \\ 90 & 8.2-12.4 & 2.82 \\ 75 & 10-15 & 3.09 \\ 62 & 12.4-18 & 2.40 \\ 51 & 15-22 & 2.02 \\ 42 & 18-26.5 & 1.27 \\ 34 & 22-33 & 1.34 \\ 28 & 26.5-40 & 1.08 \\ 22 & 33-50 & 0.87 \\ 19 & 40-60 & 0.80 \\ 15 & 50-75 & 0.51 \\ 12 & 60-90 & 0.37 \\ 10 & 75-110 & 0.31\end{array}$

The reflection of the aperture as seen from the $f$ lare is a result of the edge diffraction at $B$ in figure 2 and figure 4. The magnitude of the reflection is given by (see Appendix A)

$$
\Gamma_{a p}=0.0912 / B^{1.22}
$$

where

$$
B \equiv b / \lambda
$$


and $b$ is the narrow (E-plane) dimension of the aperture. For the aperture reflection to be less that 0.01 equation (1.4) leads to the approximation

$$
B=6 .
$$

This equation and equation (1.5) determine the narrow aperture dimension in figure 4 . To further reduce the aperture reflection quarter-round matching sections are attached to the $\mathrm{H}$ edges of the horn aperture perpendicular to the page at $B$ in figure 4 (see figure 1 also). Analysis [3] indicates that if the radius of the quarter-rounds is $3 \lambda$ (or greater) the edge diffraction is greatly reduced.

\section{Braun Equations}

Braun [4] specifies a set of relationships which, starting with a given gain, lead to an optimum horn design with approximately equal $\mathrm{E}-$ and $\mathrm{H}$-plane beamwidths where the flare in both planes join the wg portion of the horn in a simple butt joint. The starting point for the noise standard horn design is equations (1.4) and (1.5), however, since an optimum horn gain is less important than obtaining a small internal aperture reflection. The Braun equations lead directly to

$$
A=468 B / 346
$$

and

$$
l_{e}=57600 A B \lambda /(346 \times 468)
$$

where $A$ is the normalized $(a / \lambda)$ broad dimension of the aperture, and $l_{e}$ is the $\mathrm{E}$-plane flare length in figure 4. The corresponding $\mathrm{H}$-plane flare length is

$$
l_{h}=l_{e}\left[\left(1-b^{2} / 4 l_{e}^{2}\right)\left(\left(1-b_{0} / b\right) /\left(1-a_{0} / a\right)\right)^{2}+a^{2} / 4 l_{e}^{2}\right]^{1 / 2} .
$$

An approximate expression for the resulting gain $g$ is

$$
g=10^{6} A B /(346 \times 468) .
$$

It is clear from figure 4 and the equivalent figure for the $\mathrm{H}$-plane that the flare angles are given by the equations

$$
\phi_{e}=\sin ^{-1}\left(b / 2 l_{e}\right)
$$

and

$$
\phi_{h}=\sin ^{-1}\left(a / 2 l_{h}\right) .
$$

The corresponding $r_{e}$ and $r_{h}$ are then found from equation (1.2). 


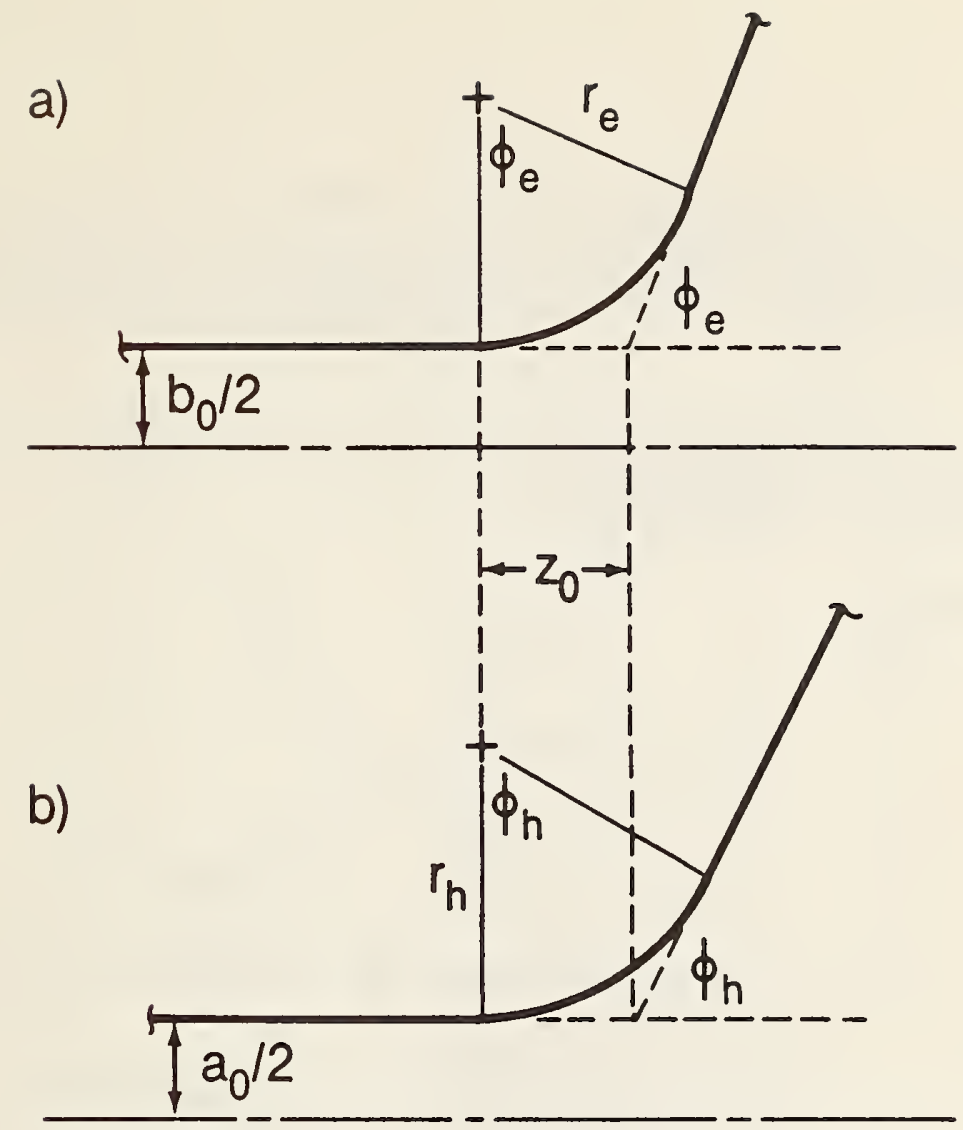

Figure 3. Cross sections of the upper halves of the E-plane (a) and H-plane (b) wg-flare transitions.

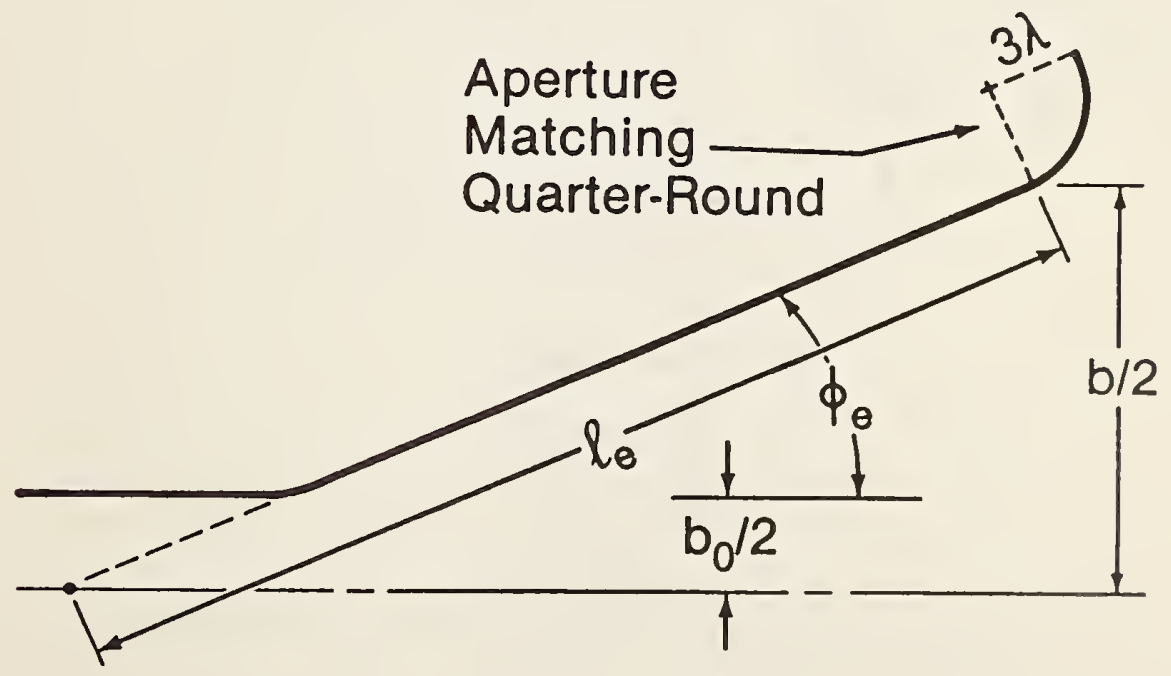

Figure 4. A cross section of the upper half of the E-plane interior surface. 


\section{Sundry Equations}

The fundamental equations relating the electrical requirements of the horn to the internal horn dimensions have been presented in the previous two sections. Following are a number of derived equations that, although easily obtained, are included here for completeness and their usefulness in calculating machine drawing dimensions.

Figures 5 and 6 show cross sections of the $\mathrm{E}$ - and $\mathrm{H}$-planes respectively in which the various dimension designations are self explanatory from previous discussions.

E-Plane Dimensions (figure 5)

$$
\begin{gathered}
\rho_{e}=b_{0} / 2 \sin \phi_{e} \\
x_{2}=x_{1}+z_{0} \\
\Delta x_{e}=r_{e} \sin \phi_{e}-z_{0} \\
\Delta y_{e}=r_{e}\left(1-\cos \phi_{e}\right) \\
l_{3}=\left(l_{e}-\rho_{e}\right) \cos \phi_{e} \\
x_{5}=x_{2}+\Delta x_{e} \\
x_{6}=x_{2}+l_{3} \\
x_{7}=x_{6}-3 \lambda \sin \phi_{e} \\
y_{7}=b / 2+3 \lambda \cos \phi_{e} \\
y_{e}=c_{1 e}+c_{2 e}\left(x-x_{1}\right)
\end{gathered}
$$

H-Plane Dimensions (figure 6)

$$
\begin{gathered}
\rho_{h}=a_{0} / 2 \sin \phi_{h} \\
\Delta x_{h}=r_{h} \sin \phi_{h}-z_{0} \\
\Delta y_{h}=r_{h}\left(1-\cos \phi_{h}\right) \\
l_{3}=\left(l_{h}-\rho_{h}\right) \cos \phi_{h} \\
x_{4}=x_{2}+\Delta x_{h} \\
y_{h}=c_{1 h}+c_{2 h}\left(x-x_{1}\right)
\end{gathered}
$$




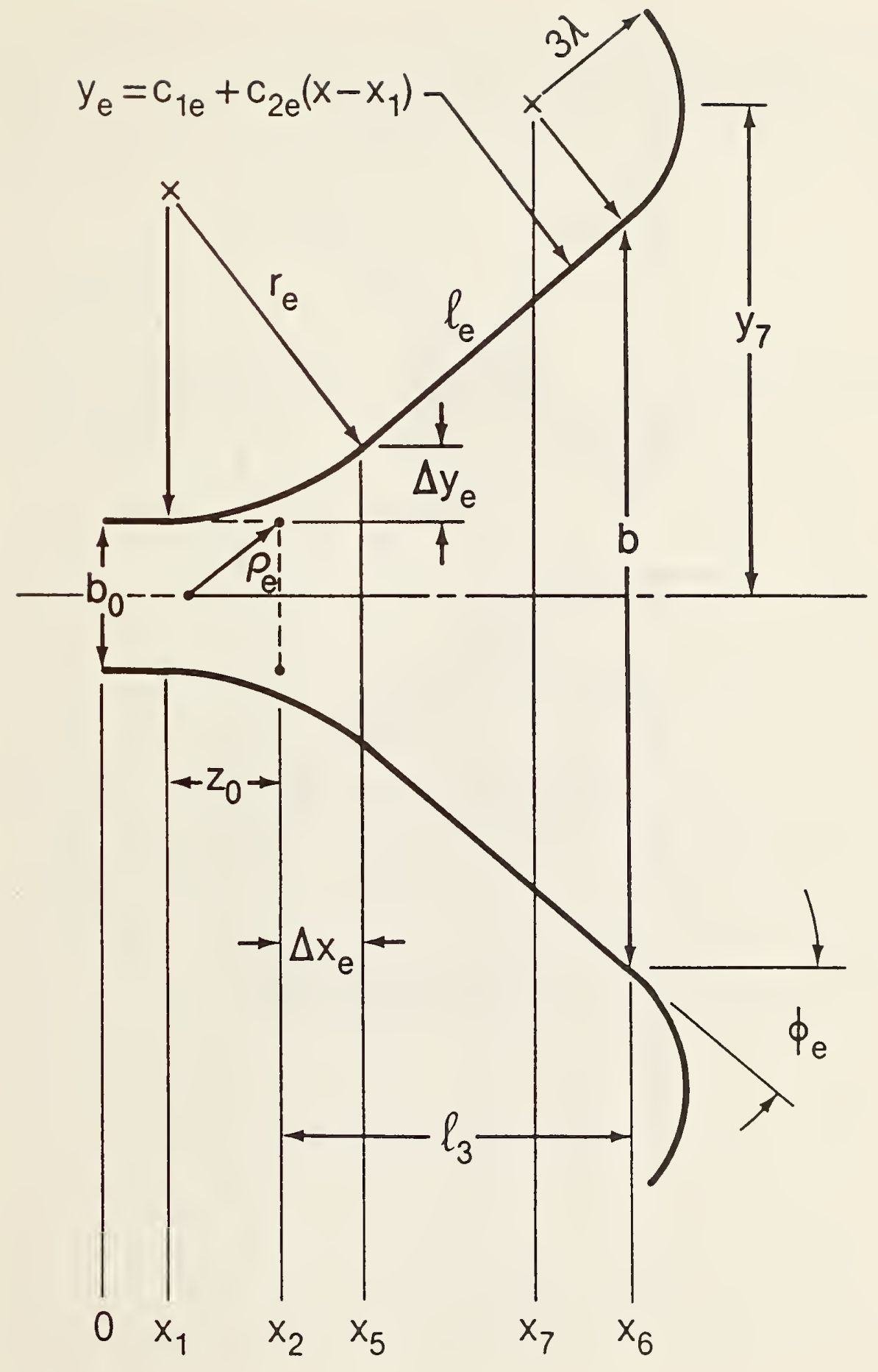

Figure 5. Cross section of the internal $\mathrm{E}$-plane surface. 


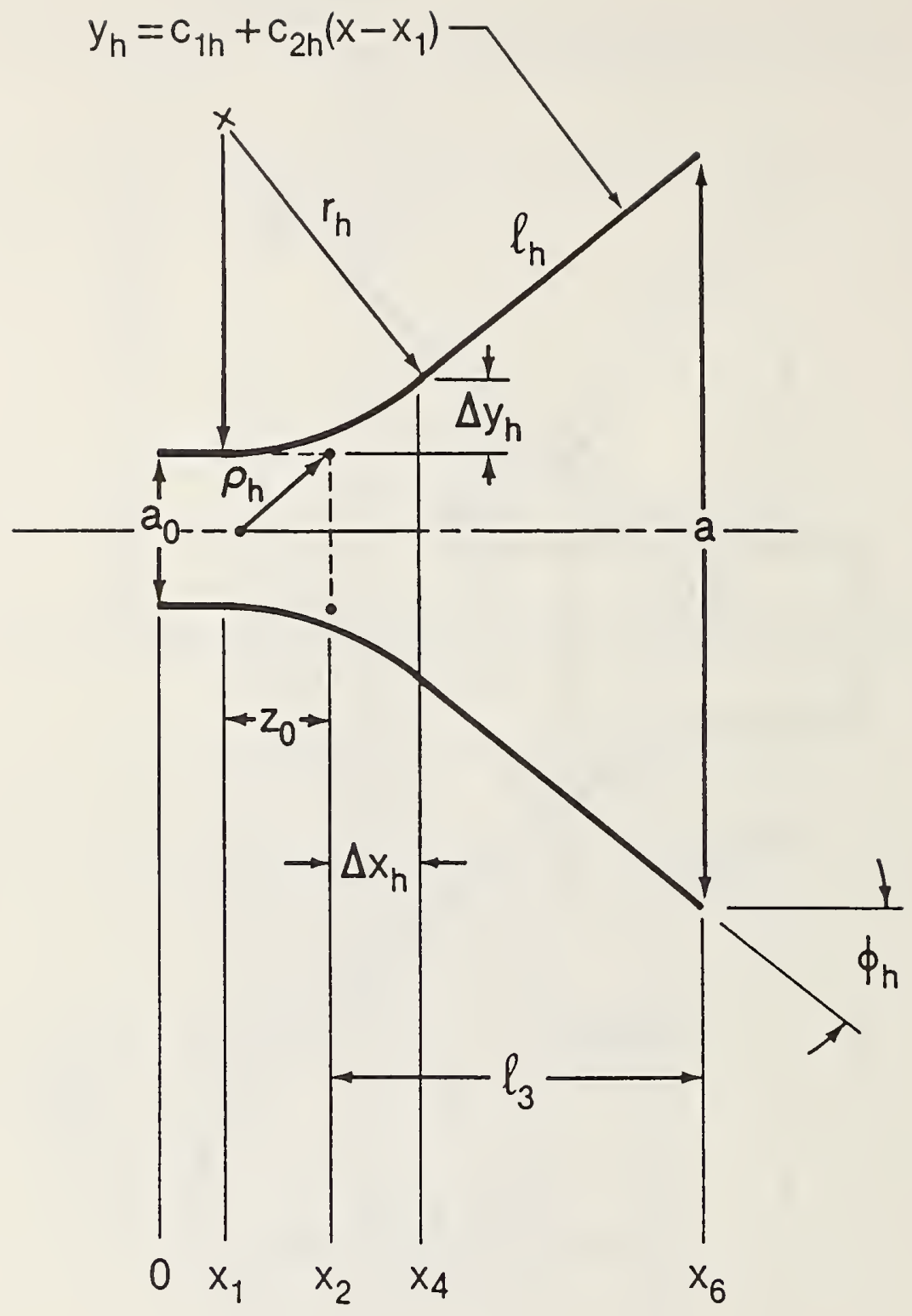

Figure 6. Cross section of the internal $\mathrm{H}$-plane surface. 


\section{Results}

Figure 7 is a photograph of the WR10 horn pickup that was designed and constructed according to the equations presented which ensure low internal reflections and an accurately calculable attenuation. Figure 8 is an isometric drawing of the same horn. The total internal reflection including the wg-flare transition and the aperture was measured to be less than 0.001 . Analysis [1] shows the attenuation calculation to be accurate to $\pm 0.01 \%$.

\section{Acknowledgments}

The Space Systems \& Command, Control, \& Communications, USAF, Washington, D.C.; and The Naval Ocean Systems Center (NOSC), San Diego, California funded much of the work leading to the millimeter wave horn pickup designs. 


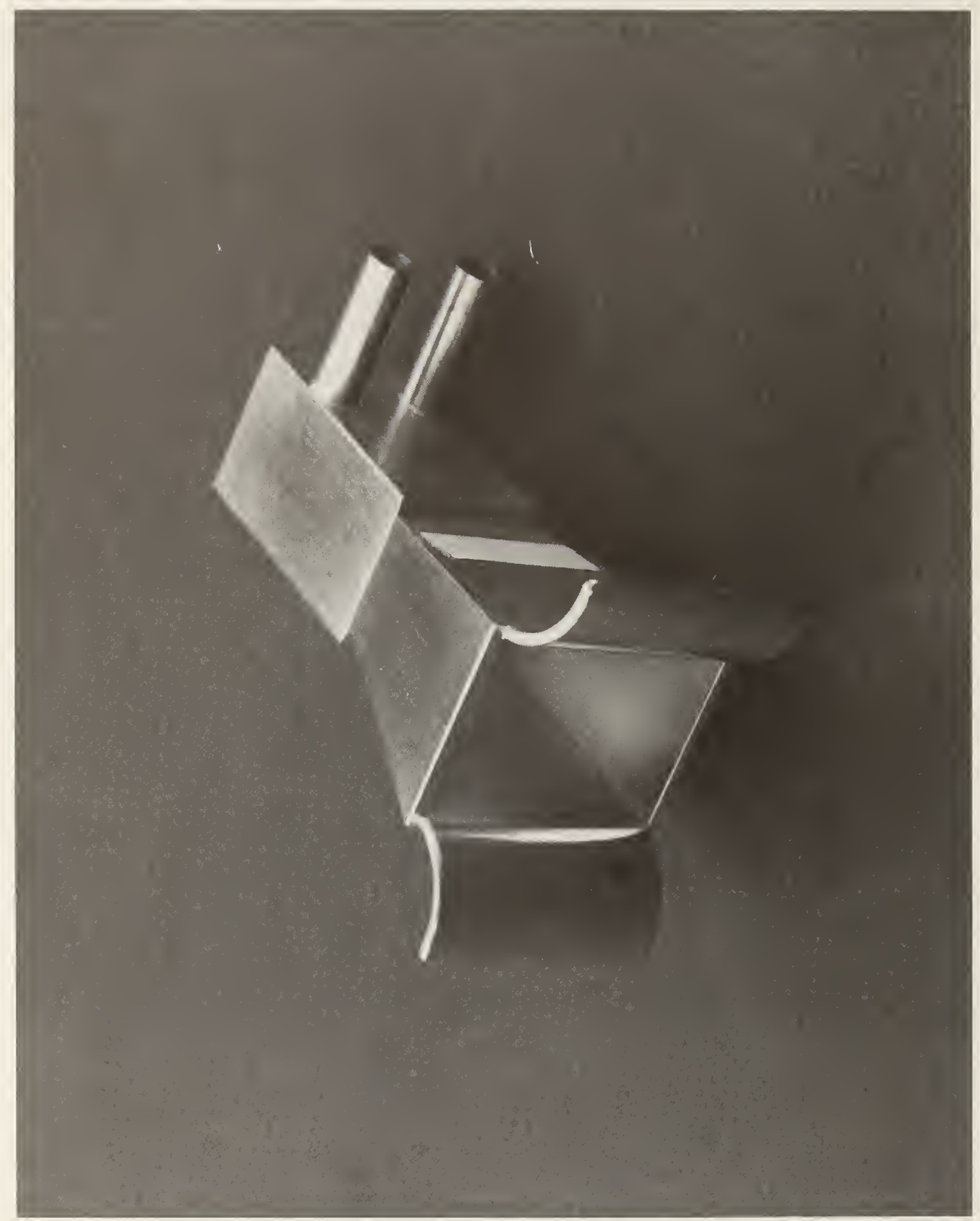

Figure 7. Photograph of the WR10 millimeter wave horn pickup. 


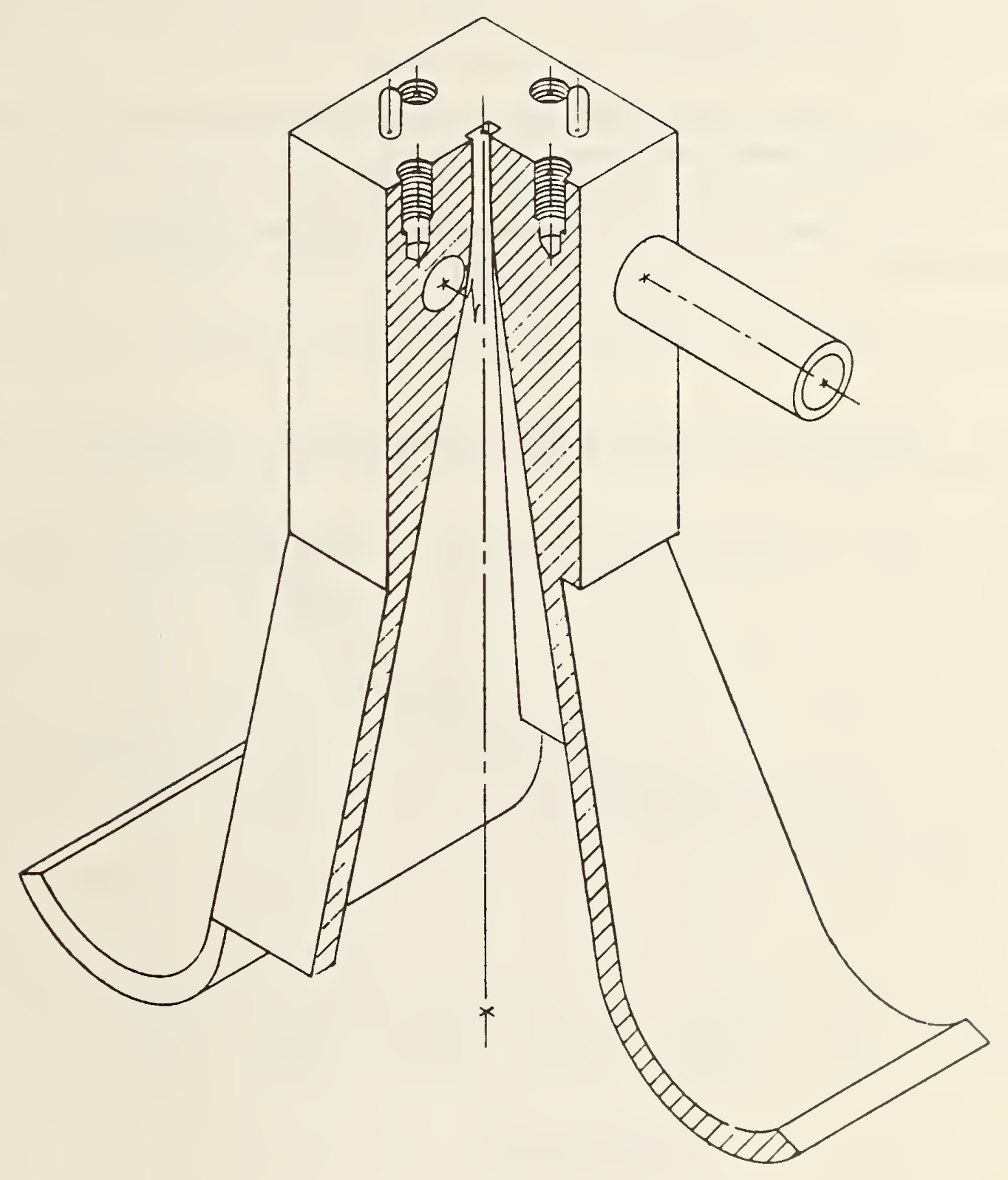

Figure 8. Isometric view of the WR10 millimeter wave horn pickup. 


\section{References}

[1] Daywitt, W. C. Design and error analysis for the WR10 thermal noise standard. Nat. Bur. Stand. (U.S.) Tech Note 1071; 1983 December.

[2] Terzuoli, A. J., Jr.; Peters, L., Jr. VSWR properties of E-plane dihedral corrugated horns. IEEE Trans., AP-26, No. 2: 236-239; 1978 March.

[3] Burnside, W. D.; Chuang, C. W. An aperture-matched horn design. IEEE Trans., AP-30, No.4: 790-796; 1982 July.

[4] Braun, E. H. Some data for the design of electromagnetic horns. IEEE Trans., AP-4: 29-31; 1956 January.

[5] Jull, E. V. Reflection from the aperture of a long E-plane sectoral horn. IEEE Trans., $A P-20$, No.1: 62-86; 1972 January.

[6] Jull, E. V. Errors in the predicted gain of pyramidal horns. IEEE Trans., AP-21, 25-31; 1973 January. 


\section{Appendix A: Aperture Reflection}

Jull $[5]$ derives the following expression for the magnitude of the reflection seen from the flare portion of a sectoral horn:

$$
\Gamma_{a p}=1 / 4 \phi_{e} k l_{e}
$$

where $\mathrm{k}$ is the free space wavenumber $(2 \pi / \lambda)$. Figure A1 shows a comparison of this formula with reflection data [6] from a pyramidal horn aperture as a function of $4 \phi_{e} k l_{e}$, where the formula is plotted as the solid curve in the figure. The dashed curve is a least-squares fit through the data as a function of $\left(4 \phi_{e} k l_{e}\right)^{-c}$, where the constant $c$ was found to be 1.22 with a correlation coefficient of 0.98 for the fit. Recognizing that $2 \phi_{e} l_{e}$ is the narrow aperture dimension $b$ for small $\phi_{e}$ leads to equation (1.4), where $B$ is the normalized aperture dimension.

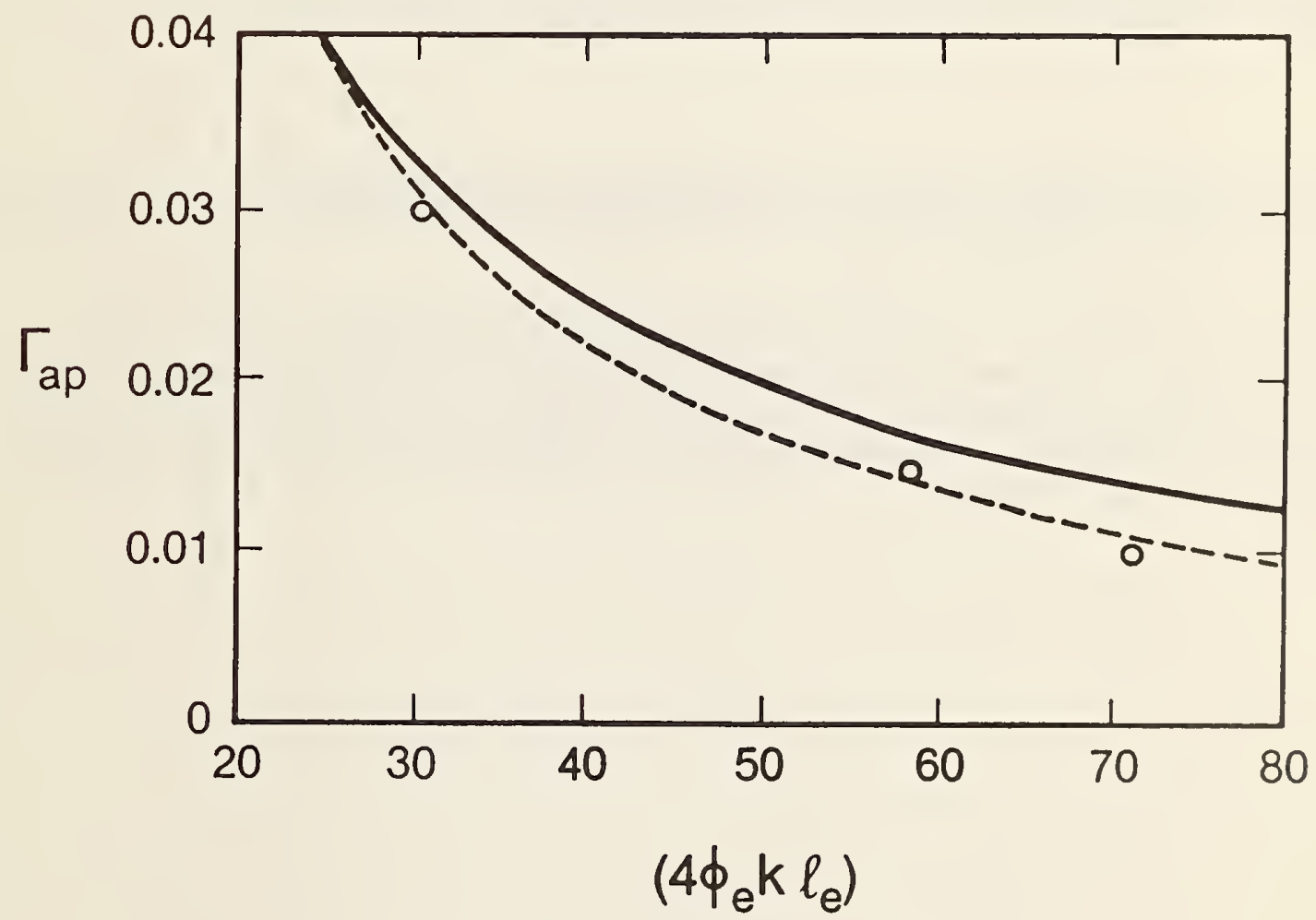

Figure A1. Internal aperture reflection for a pyramidal horn. 
NBS-11 $4 A$ (REV. $2-8 \mathrm{C}$ )

S. OEPT, OF COMM,

BIBLIOGRAPHIC DATA

SHEET (See instructions)

4. TITLE AND SUBTITLE

HORN DESIGN EQUATIONS FOR THE NBS HORN-TYPE NOISE STANDARDS

5. $\operatorname{AUTHOR}(\mathrm{S})$

William C. Daywitt

6. PERFORMING ORGANIZATION (If joint or other than NBS, see instructions)

NATIONAL BUREAU OF STANDARDS

DEPARTMENT OF COMMERCE

WASHINGTON, D.C. 20234

9. SPONSORING ORGANIZATION NAME AND COMPLETE ADDRESS (Street, City, State, ZIP)

The Space Systems \& Command, Control, \& Communications

USAF, Washington, DC

and

The Naval Ocean Systems Center (NOSC), San Diego, California

10. SUPPLEMENTARY NOTES

Document describes a computer program; SF-185. FIPS Software Summary, is attached.

11. ABSTRACT (A 200-word or less factual summary of most significant information. If document includes a significant bibliography or literature survey, mention it here)

Equations are given for calculating the interior dimensions of the horn pickup in the NBS millimeter wave noise standards. These dimensions insure negligible internal horn reflections, resulting in an accurate calculation of the horn attenuation. Measurements in the WR10 horn show a reflection of magnitude less than 0.001 .

12. KEY WORDS (Six to twelve entries; alphabetical order; capitalize only proper names; and separate key words by semicolons) electromagnetic horn; millimeter wave; noise source; reflection coefficient

13. AVAILABILITY

[X] Unlimited

For Official Distribution. Do Not Release to NTIS

Order From Superintendent of Documents, U.S. Government Printing Office, Washington, D.C. 20402.

X Order From National Technical Information Service (NTIS), Springfield, VA. 22161
14. NO, OF

PRINTED PAGES

20

15. Price 



